\title{
Relationship Between IL-18 and Bone Metastasis in Female Breast Cancer
}

\author{
Erdinç NAYIR, ${ }^{1}$ Sinan AYGÜN, ${ }^{2}$ Alper ATA, ${ }^{3}$ Ali ARICAN ${ }^{4}$ \\ 'Department of Oncology, Kahramanmaraş Necip Fazıl City Hospital, Kahramanmaraş-Turkey \\ ${ }^{2}$ Department of Internal Diseases, Tarsus Medical Park Hospital, Mersin-Turkey \\ ${ }^{3}$ Department of Oncology, Tarsus Medical Park Hospital, Mersin-Turkey \\ ${ }^{4}$ Department of Oncology, Mersin University Faculty of Medicine, Mersin-Turkey
}

\begin{abstract}
OBJECTIVE
Breast cancer is a metastatic disease that frequently (in approximately $70 \%$ of cases) affects the skeletal system. The aim of the present study was to compare serum IL-18 levels in breast cancer patients with and without bone metastases with healthy controls.
\end{abstract}

\section{METHODS}

Included were a total of 154 female breast cancer patients with bone metastases ( $\mathrm{n}=53$; Group 2) and without bone metastases ( $\mathrm{n}=51$; Group 1), as well as 50 healthy control subjects (Group 3). Serum IL-18 levels were compared among the groups.

\section{RESULTS}

Mean serum IL-18 levels were significantly different between Groups 1 and 3 ( $\mathrm{p}<0.001)$, Groups 2 and $3(\mathrm{p}<0.001)$, and Groups 2 and $1(\mathrm{p}=0.020)$. In receiver operating characteristic $(\mathrm{ROC})$ curve analysis performed between Groups 1 and 2, sensitivity of serum IL-18 levels in patients with bone metastases was nearly 26 percent.

\section{CONCLUSION}

Lower rates of IL-18 sensitivity were detected in breast cancer patients with bone metastasis.

Keywords: IL-18; bone metastasis; breast cancer.

Copyright $\odot$ 2016, Turkish Society for Radiation Oncology

\section{Introduction}

Breast cancer is the most frequently occurring type of cancer in women, and the most common cause of cancer-related mortality after lung cancer. One of every 9 women has a risk of developing invasive breast cancer during her lifetime.[1] Nearly 25\% of breast cancer metastases initially involve bone, and bone metastases are observed in nearly $70 \%$ of patients with metastatic breast cancer. Bone metastases are important etiological factors for morbidity and mortality. With the presence of bone metastases secondary to breast cancer, pain, hypercalcemia, fractures, and nerve compression are frequently observed.[2]

Tumor biology should be better understood, and mechanisms of the metastatic process should be more comprehensively investigated in an effort to decrease development of bone metastasis in breast cancer, emergence of related complications, and mortality rates. 


Table 1. Distribution of number and ages of female study participants according to group
\begin{tabular}{lcc} 
Group & Number of volunteers $\mathbf{n = 1 5 4}$ & Mean $\mathbf{1 5 D}$ age of volunteers \\
\hline 1 & 51 & $52.65 \pm 9.54$ \\
2 & 53 & $55.04 \pm 13.45$ \\
3 & 50 & $53.12 \pm 12.61$ \\
\hline
\end{tabular}

The aim of the present study was to compare serum IL-8 levels in breast cancer patients with and without bone metastases and healthy individuals. In consideration of potentially emergent outcomes, degree of sensitivity of serum IL-18 levels in the detection of bone metastases in breast cancer patients and optimal treatment strategies are discussed.

\section{Materials and Methods}

\section{Sampling method}

A total of 104 female patients with breast cancer who presented to the Outpatient Clinic of the Mersin University Faculty of Medicine Department of Medical Oncology between March 2011 and March 2012 were included. Patients aged over 18 years with histopathologically confirmed breast cancer were divided into Groups 1 and 2. Fifty-one patients, including some in remission and some without bone metastases who regularly attended follow-up visits, were selected for Group 1. Fifty-three patients, included in Group 2, had bone metastases. Number and location of bone metastases were not taken into consideration. Patients without bone metastases, but with metastases in different organs were not included. Fifty healthy women who had consulted the hospital within the aforementioned time interval were included as the control group, Group 3. Controls were women aged over 18 years with no known chronic or autoimmune disease, or active infection.

From the volunteers, 5-mL fresh blood samples were drawn into flat-bottom test tubes, and centrifuged at $4000 \mathrm{rpm}$ for 10 minutes at ambient temperature to separate sera. Serum samples were conserved in Eppendorf tubes at $-250 \mathrm{C}$ until analysis. The samples to be analyzed were pipetted out from Eppendorf tubes at $-250 \mathrm{C}$ and left to thaw at room temperature before analyses were performed. Human IL-18 was analyzed with a DSX Automated Microelisa Processing System (Dynex Technologies Inc., Chantilly, VA, USA), using human IL-18 enzyme-linked immunosorbent assay (ELISA) kit (MBL Ltd. code no: 7620) and sandwich ELISA method. Reference range was $36.1-257.8 \mathrm{pg} / \mathrm{mL}$.

\section{Statistical analysis}

Categorical variables were expressed as numbers and percentages, while continuous variables were expressed as mean \pm SD. One-way analysis of variance was used for intergroup comparison of IL-18 levels and patient ages. If intergroup differences were found, post-hoc analysis with Bonferroni correction was performed. Receiver operating characteristic (ROC) curve analysis was used to obtain cutoff values for IL-18. Level of significance of statistical analyses was accepted as $\mathrm{p}<0.05$.

\section{Results}

Mean ages among the groups were similar (Table 1).

Distribution of cancer stages of Group 1 patients were: stage I, 24\%; stage II, $49 \%$; stage III, $27 \%$. All patients had metastatic disease, and were included in stage IV. Regarding histopathological diagnosis, invasive ductal carcinoma was the most common diagnosis in Groups 1 and 2 (83\%). Invasive lobular carcinoma (10\%), invasive papillary carcinoma (6\%), and medullary carcinoma (1\%) were also observed.

Mean serum IL-18 level of Group 2 (1528.38 \pm 1081.28 $\mathrm{pg} / \mathrm{mL})$ was higher than that of Group 1 (1146.16 \pm 495.09 $\mathrm{pg} / \mathrm{mL})$. Mean serum IL-18 levels of Groups 1 and 2 were higher than that of Group $3(480.33 \pm 234.62 \mathrm{pg} /$ $\mathrm{mL}$; Table 3)

A statistically significant difference was found among serum IL-18 levels $(\mathrm{p}<0.001)$. Mean serum IL18 levels of Groups 3 and 2 were statistically significantly different $(\mathrm{p}<0.001)$. Mean serum IL-18 levels of Groups 3 and 1 were statistically significantly different $(\mathrm{p}<0.001)$, as were those of Groups 1 and $2(\mathrm{p}=0.020)$.

Table 2. Comparison of hormone receptor and HER2 positivities in Groups 1 and 2

\begin{tabular}{lcc} 
& Group 1 & Group 2 \\
\hline Estrogen receptor positivity & $62 \%$ & $79 \%$ \\
Progesterone receptor positivity & $56 \%$ & $67 \%$ \\
HER 2 positivity & $35 \%$ & $24 \%$ \\
Triple negative & $13 \%$ & $8 \%$ \\
Triple positive & $17 \%$ & $15 \%$ \\
\hline
\end{tabular}


Table 3. IL-18 values (mean $\pm \mathrm{SD}$ ) among the groups

\begin{tabular}{|c|c|c|c|}
\hline & $\begin{array}{c}\text { Group } 1 \\
\text { Mean } \pm S D \\
(n=51)\end{array}$ & $\begin{array}{c}\text { Group } 2 \\
\text { Mean } \pm \text { SD } \\
(n=53)\end{array}$ & $\begin{array}{c}\text { Group } 3 \\
\text { Mean } \pm \text { SD } \\
(n=50)\end{array}$ \\
\hline IL-18 level & $\begin{array}{c}1146.16 \pm 495.09 \\
(\mathrm{pg} / \mathrm{mL})\end{array}$ & $\begin{array}{c}1528.38 \pm 1081.28 \\
(\mathrm{pg} / \mathrm{mL})\end{array}$ & $\begin{array}{c}480.33 \pm 234.62 \\
(\mathrm{pg} / \mathrm{mL})\end{array}$ \\
\hline
\end{tabular}

As a result of ROC curve analysis, cutoff value of IL18 in breast cancer patients with and without bone metastasis was $1773.63 \mathrm{pg} / \mathrm{mL}$. Diagnostic value of IL-18 level in the detection of bone metastasis when used as a marker is shown in Table 4.

Area under the curve (AUC) value for serum IL-18 levels in Groups 1 and 2 was $0.576(\mathrm{p}=0.1782)$. An AUC value of less than 0.60 signifies that this test will not be statistically useful when discriminating between breast cancer patients with and without bone metastases.

\section{Discussion}

Prognostic parameters are still a subject of debate. In clinical practice, most important prognostic and predictive information regarding breast cancer is obtained from histopathological evaluation (incorporating size of tumor, extent of axillary lymph node involvement, presence of lymphatic and vascular invasion, histological grading of the tumor, and estrogen/progesterone status).[3] Breast cancer patients are most commonly lost due to distant metastases, and bone metastases develop in in approximately 70\% of these cases.[4] The determination of prognostic factors is of the utmost importance, so that the disease may be detected at an early stage, potential metastases may be evaluated, existing metastases may be optimally monitored, and convenient treatment strategies may be determined. The current lack of auxiliary markers to aid in the detection of bone metastases in breast cancer has lead researchers to conduct new studies.

Increased levels of serum IL- 8 in some cancer patients has been reported, and it has been determined that disease progression in patients with increased serum IL18 levels is more fatal. Takubo et al. demonstrated that non-Hodgkin's lymphoma patients with serum IL-18 levels over 2000 pg/mL were at higher risks. [5] Kawabata et al. reported that gastric cancer patients with higher serum IL-18 levels had shorter survival times. 6 These results suggest that serum IL-18 levels may be used as a prognostic factor in some cancer patients. However, while IL-18 has been associated with some cancer types, the mechanisms of cancer pathogenesis and antitumor activity have yet to be made clear. Still, IL-18 may presumably be an important marker in the progression of breast cancer,[6] as serum IL-18 levels in breast cancer patients who developed bone metastases were found to be significantly higher in several studies.[7,8]

In light of these results, the usefulness of serum IL18 as a marker of the potential development of bone metastases in breast cancer patients was presently investigated.

Serum IL-18 levels were compared among breast cancer patients with and without bone metastases and healthy women. Breast cancer patients with other organ metastases were not included. In a similar study conducted by Soheir et al. in 2005, no significant difference in serum IL-18 levels was found between breast cancer patients with bone or other organ metastases. [8] However, in the present study, serum IL-18 levels of all breast cancer patients (with and without metastases) were found to be higher than those of the healthy controls (Table 3). Serum IL-18 levels in the group with bone metastases were found to be significantly higher $(\mathrm{p}=0.020)$. In a similar study conducted by Günel et al. in 2002, serum IL-18 levels in the metastatic and nonmetastatic groups were found to be higher than those of the healthy group, while serum IL-18 levels of the group with bone metastases were higher than those of the nonmetastatic group.[7] However, in several studies, some performed by Günel et al., breast cancer patients with metastases in other organs constituted a

Table 4. Diagnostic value of serum IL-18 level

\begin{tabular}{lcccrr} 
Cytokine & Cutoff value $(\mathbf{p g} / \mathbf{m L})$ & Area under curve & Sensitivity (\%) & Specificity (\%) & p \\
\hline IL-18 & 1773.63 & 0.576 & 26.4 & 96.1 & 0.17 \\
\hline
\end{tabular}


separate study group. Still, serum IL-18 levels of breast cancer patients with bone metastases were statistically significantly higher, compared to those of breast cancer patients with other organ metastases.[7,9] Following the important discovery that primary osteoblasts can also secrete IL-18 receptor components, many authors have suggested that osteoblasts are target cells in IL-18 response and that IL-18 exerts a physiological effect on osteogenic cells. [10]

IL-18 exerts its effects on osteoblasts, not via production of INF-y, but rather via production of granulocyte macrophage colony-stimulating factor (GM-CSF).[11] Increased GM-CSF also induces dose-related increases in the proliferation rate of human osteoblasts.[12] IL-18 can inhibit osteoclastogenesis by increasing osteoprotegerin in stromal or osteoblastic cells. [10] In addition to its physiological interactions with osteogenic cells, IL18 also plays a role in pathological processes. In the development of bone metastasis in breast cancer patients, as an autocrine defense mechanism, the organism releases IL-18 from osteoclasts and osteoblasts.[11] This phenomenon can be thought to justify the detection of higher IL-18 levels in the presence of bone metastasis. However, it should be investigated further in comprehensive studies.

As evidenced by theoretical experiments, IL-18 can inhibit development of osteolytic metastases of human lung cancer or human breast cancer cells. [13,14] In addition, initial treatment with recombinant IL-18 or IL18 binding protein reportedly decreased the number of distant metastases in mice cancer models.[15]

As mean serum IL-18 values of patients with bone metastases were significantly higher than those without metastases $(p=0.020)$ in the present study, it can be said that IL-18 may be useful in the detection of bone metastases. The cutoff value of serum IL-18 for the groups with and without bone metastases was $1773.63 \mathrm{pg} / \mathrm{mL}$, and keeping in mind that patients with serum IL-18 levels above this cutoff value had bone metastases, nearly $27 \%$ of this group of patients exceeded the cutoff value. However, other patients with serum IL-18 values below the cutoff had conclusively confirmed bone metastases. Therefore, serum IL-18 may not be a sensitive marker in the monitorization of breast cancer patients with bone metastases. At the same time, the lower sensitivity of IL-18 in the present study may be related to bisphosphonates used by breast cancer patients with bone metastases.

Bisphosphonates, which effect bony structures via pathways similar to those involved in the mechanism of IL-18, also exert an impact on the secretion of RANKL, an osteoclast differentiation factor.[16] RANKL secreted from osteoblastic precursor cells binds to RANK receptors released from osteoclasts and osteoclast precursors.[17] The activity of RANKL is blocked by OPS, which prevents bone resorption and acts as an antagonist receptor of RANKL.[18] With this mechanism, bisphosphonates prevent osteoclastic bone resorption, as is done by IL-18. It has been demonstrated in experimental studies using mice that bisphosphonates decrease skeletal metastases and tumor burden of bone. $[19,20]$

Considering these results, it can be concluded that serum IL-18 levels will decrease in response to decreased tumor burden in the bone, and that bone metastases will regress in patients using bisphosphonates. This phenomenon, which narrows the gap between IL-8 levels in groups with and without bone metastases, may explain the decreased sensitivity of this test. The authors believe that further studies will yield more accurate outcomes and conclude the debate surrounding this issue.

\section{Disclosure Statement}

The authors declare no conflicts of interest.

\section{References}

1. Anthony S. Fauci, Eugene Braunwald, Dennis L. Kasper Breast Cancer Harrison's Principles of internal Mehdicine 17th Ed. New York: The McGraw-Hill Companies, Inc. 2008.

2. Guise TA. Molecular mechanisms of osteolytic bone metastases. Cancer 2000;88(12 Suppl):2892-8.

3. Fisher B, Anderson S, Bryant J, Margolese RG, Deutsch $\mathrm{M}$, et al. Twenty-Year Follow-up of a Randomized Trial Comparing Total Mastectomy, Lumpectomy, and Lumpectomy plus Irradiation for the Treatment of Invasive Breast Cancer. N Engl J Med 2002;347:1233-41.

4. Coleman RE. Clinical features of metastatic bone disease and risk of skeletal morbidity. Clin Cancer Res 2006;12(20 Suppl):6243-9.

5. Takubo T, Kumura T, Nakao T, Nakamae H, Aoyama Y, Nishiki S, et al. Comparative study on complete remission rate and overall survival in three groups classified based on the serum interleukin-18 level in non-Hodgkin's lymphoma patients. Acta Haematol 2000;104(4):220-2.

6. Eissa SA, Zaki SA, El-Maghraby SM, Kadry DY. Importance of serum IL-18 and RANTES as markers for breast carcinoma progression. J Egypt Natl Canc Inst 2005;17(1):51-5. 
7. Günel N, Coşkun U, Sancak B, Günel U, Hasdemir O, Bozkurt S. Clinical importance of serum interleukin-18 and nitric oxide activities in breast carcinoma patients. Cancer 2002;95(3):663-7.

8. Eissa SA, Zaki SA, El-Maghraby SM, Kadry DY. Importance of serum IL-18 and RANTES as markers for breast carcinoma progression. J Egypt Natl Canc Inst 2005;17(1):51-5.

9. Okamoto M, Azuma K, Hoshino T, Imaoka H, Ikeda J, Kinoshita T, et al. Correlation of decreased survival and IL-18 in bone metastasis. Intern Med 2009;48(10):763-73.

10. Makiishi-Shimobayashi C1, Tsujimura T, Iwasaki T, Yamada N, Sugihara A, Okamura H, et al. Interleukin-18 up-regulates osteoprotegerin expression in stromal/osteoblastic cells. Biochem Biophys Res Commun 2001;281(2):361-6.

11. Udagawa N, Horwood NJ, Elliott J, Mackay A, Owens J, Okamura $\mathrm{H}$, et al. Interleukin-18 (interferon-gamma-inducing factor) is produced by osteoblasts and acts via granulocyte/macrophage colony-stimulating factor and not via interferon-gamma to inhibit osteoclast formation. J Exp Med 1997;185(6):1005-12.

12. Modrowski D, Lomri A, Marie PJ. Endogenous GMCSF is involved as an autocrine growth factor for human osteoblastic cells. J Cell Physiol 1997;170(1):3546.

13. Nakata A, Tsujimura $T$, Sugihara A, Okamura $H$, Iwasaki T, Shinkai K, et al. Inhibition by interleukin 18 of osteolytic bone metastasis by human breast cancer cells. Anticancer Res 1999;19(5B):4131-8.

14. Iwasaki T, Yamashita K, Tsujimura T, Kashiwamura S,
Tsutsui H, Kaisho T, et al. Interleukin-18 inhibits osteolytic bone metastasis by human lung cancer cells possibly through suppression of osteoclastic boneresorption in nude mice. J Immunother 2002;25 Suppl 1:52-60.

15. Cao Q, Cai W, Niu G, He L, Chen X. Multimodality imaging of IL-18--binding protein-Fc therapy of experimental lung metastasis. Clin Cancer Res 2008;14(19):6137-45.

16. Mackie PS, Fisher JL, Zhou H, Choong PF. Bisphosphonates regulate cell growth and gene expression in the UMR 106-01 clonal rat osteosarcoma cell line. $\mathrm{Br}$ J Cancer 2001;84(7):951-8.

17. Gao YH, Shinki T, Yuasa T, Kataoka-Enomoto H, Komori T, Suda T, et al. Potential role of cbfal, an essential transcriptional factor for osteoblast differentiation, in osteoclastogenesis: regulation of mRNA expression of osteoclast differentiation factor (ODF). Biochem Biophys Res Commun 1998;252(3):697-702.

18. Hsu H, Lacey DL, Dunstan CR, Solovyev I, Colombero A, Timms E, et al. Osteoprotegerin (OPG) ligand is a cytokine that regulates osteoclast differentiation and activation. Cell 1998;93:165-76.

19. Green JR. Bisphosphonates: preclinical review. Oncologist 2004;9 Suppl 4:3-13.

20. Yamagishi S, Abe R, Inagaki Y, Nakamura K, Sugawara $\mathrm{H}$, Inokuma D, et al. Minodronate, a newly developed nitrogen-containing bisphosphonate, suppresses melanoma growth and improves survival in nude mice by blocking vascular endothelial growth factor signaling. Am J Pathol 2004;165(6):1865-74. 